\title{
Research on Information Framework of All-Life-Cycle Equipment Logistic Support
}

\author{
Jiaju $\mathrm{Wu}^{* 1}$, CuiFang Zheng ${ }^{2}$, Xinglin Zhu ${ }^{2}$, Zhengji Liu ${ }^{2}$, \\ Zheng Cheng ${ }^{2}$, Lirong Meng ${ }^{2}$ \\ ${ }^{1}$ China Academy of Engineering Physics, Institute of Computer Application. \\ Mianyang Sichuan, 621999 P.R. China. (PH) +86-131-9807-8524, IEEE member, ID: 41631773, E- \\ mail:wujj@caep.cn. \\ ${ }^{2}$ China Academy of Engineering Physics, Institute of Computer Application. \\ Mianyang Sichuan, 621999 PR. China.
}

\begin{abstract}
Keywords:equipment, all-life-cycle, logistic support,information framework
Abstract - Based on the analysis of the all-life-cycle equipment logistic support, this paper suggests that all-life-cycle equipment logistic support information start from information management without paper, gradually establish a digital platform of equipment logistic support, then construct integrated data environment, realize digitization, automation, networking and integration of all-life-cycle equipment information. Around the information construction goal of equipment logistic support, this paper proposes an information framework of all-life-cycle equipment logistic support and analyzes the framework component and the key realization technique.
\end{abstract}

\section{Introduction}

With the complex equipment system, equipment support has become an important factor affecting the combat effectiveness of the military forces, it has been used as the support to combat performance requirements, and occupies the equally important position, has become an important factor restricting the development of equipment system and life cycle cost. In order to meet the needs of the modern war on the damaged equipment and equipment failure, response and resume fighting requirements quickly, supportability equipment must be from the design phase synchronization is designed, and has been to the continuous improvement of equipments in the usage phase, the whole process throughout the whole life cycle of equipment. In the development process of integrated equipment support equipment system in support issues into consideration, the support design and deployment while equipment, to provide resources and support each other, and equipped with the lowest cost, the establishment of support system, meet the mission requirements usually and readiness for a series of technical and management activities of $[1,2]$.From the beginning of the 20 century 80 years, the introduction of support design in the development of F-18 aircraft in the U.S., then developed a new type of weapon B-2 bombers, SSN21 nuclear attack submarines and fighter F-22, from the beginning of the design emphasizes the design and analysis of support, will guarantee the design and weapon equipment and production process are integrated to ensure the combat readiness target weapon system [3]. Developed countries, the comprehensive protection technology has gone through a long process of development, has been gradually using information technology and digital integrated support platform to achieve the comprehensive protection of equipment design and planning. China started in 1980s by the military took the lead in introducing integrated logistics support concept, translated a number of comprehensive data protection. In 2000 years, china has gradually introduced the interactive electronic manual, support analysis, integrated support management software, the formation of related GB, GJB, the main focus of the digital integrated equipment support in specific areas of business, has not been carried out the integrated support management. As early as 90s, Europe and the United States optimize the design and implementation of equipment and equipment support product, support scheme design and evaluation, 
plan maintenance, spare parts, equipment and other support information management through the simulation technology, information technology, data processing technology, IETM technology. Based on EAGLE, ASENT, MMIS, AIMSS, Arbortext, Relex etc., software support digital integrated support platform has been a lot of applications in the U.S.

\section{Equipment integrated support business connotation}

Integrated equipment support oriented to the whole life cycle is around the equipment design and system design of the two main line, the bridge is the support analysis, requirements, equipment manufacturer, use three kinds of roles include life cycle process, as shown in fig 1:

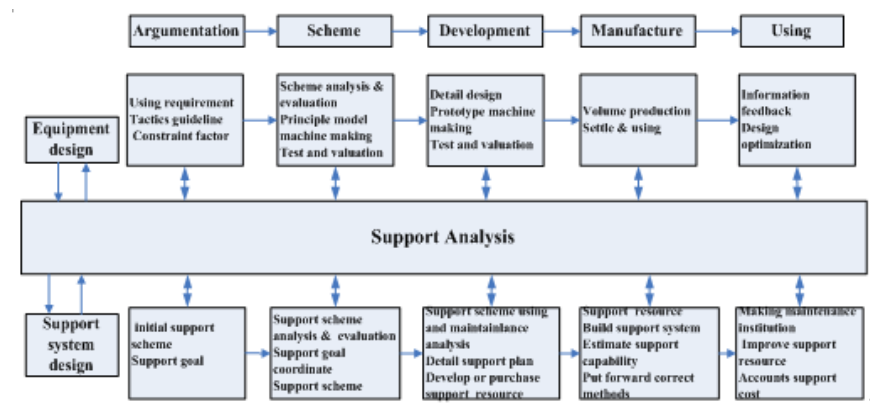

Figure 1. connotation of equipment integrated support service for the whole life cycle

To carry out the design of integrated equipment support services include support equipment, that is to carry out a comprehensive equipment reliability, maintainability, testability, support and safety and other general characteristics of analysis and design; determine the equipment support scheme and support resources, requires close collaboration between reliability and maintainability engineers and support engineers, accomplished by support analysis; provide the required support, including procurement and supply plan, provide spare parts, documents, ground support equipment and training [4]. Equipment integrated support work throughout the demonstration, program, engineering design and development, manufacturing and use of the various stages of the life cycle [5].

\section{Equipment Logistic support information objectives}

It is not enough to carry out the logistic support work of the equipment, but also need the professional management platform and software tools as support. Integrated equipment support information goal oriented life cycle is from the life cycle information paperless to start, and gradually establish equipment integrated support platform, building the integrated data environment, digitization, automation and network to realize the whole life cycle of equipment and information integration, equipment demonstration, design, manufacture, use, analysis maintenance and decommissioning of the whole life cycle of the design institutes, production units, units and bases warehouse and supporting Supplier Collaborative integration support, and ultimately achieve through the whole life cycle of information work of equipment comprehensive support to carry out the upgrading of equipment guarantee performance goals. Digital integrated support platform mainly includes support design, support analysis, support scheme, application, technical support and support management aspects including support, support in various stages of life cycle management covers equipment and relevant departments. For the whole life cycle of the equipment integrated information support objectives as shown in figure 2 : 


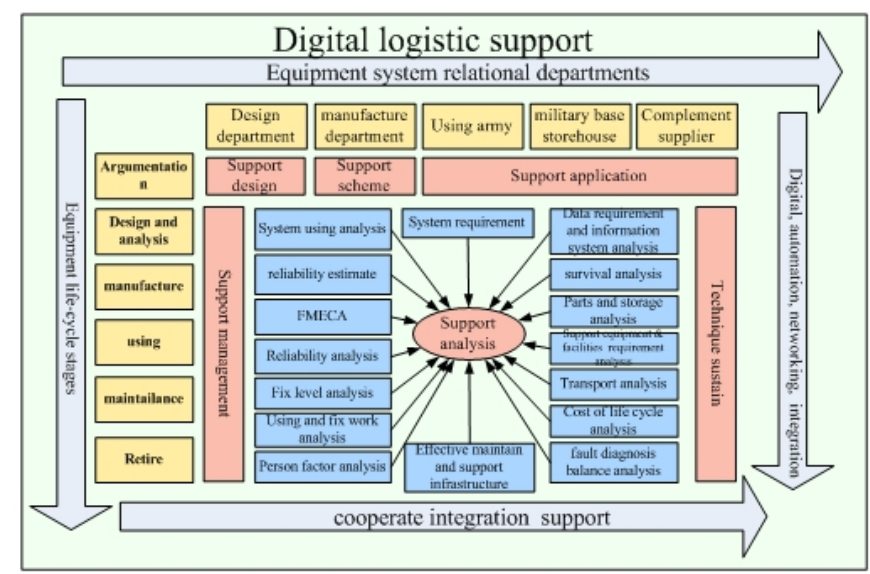

Figure 2. Equipment whole life cycle integrated lositic support information objectives

Equipment integrated support throughout the equipment demonstration, design, manufacturing, delivery, operation and maintenance, inventory and service life cycle, in all stages and equipment development and mutual relations, mutual restraint, mutual promotion. Integrated equipment support core data into product definition data and the product data support, data definition products include engineering drawings, design specifications, technical reports, analysis and test data, data support products including product data files, data reliability and maintainability, use and maintenance manual, supply and maintenance of data, support analysis and support records data elements. In the different stages of the life cycle of the equipment, the equipment integrated protection of the design institutes, production units, units, base warehouses and supporting suppliers of these data are not the same as the use of demand.

\section{Equipment integrated information framework}

According to the integrated equipment support for the whole life cycle of the connotation of business and information technology, integrated support platform is composed of three layers, which are design analysis and scheme, integrated support management and technical support, and remote application. Digital design platform and digital manufacturing platform provide the corresponding design and manufacturing data for the integrated support platform. The basic support system of support from the three aspects of the business integration platform, data center and hardware support platform integrated support platform, through the standard system, information support system and operation management system to guarantee the comprehensive support work standardization, safety and efficiency. Equipment integrated support information framework for life cycle is shown in figure 3. 


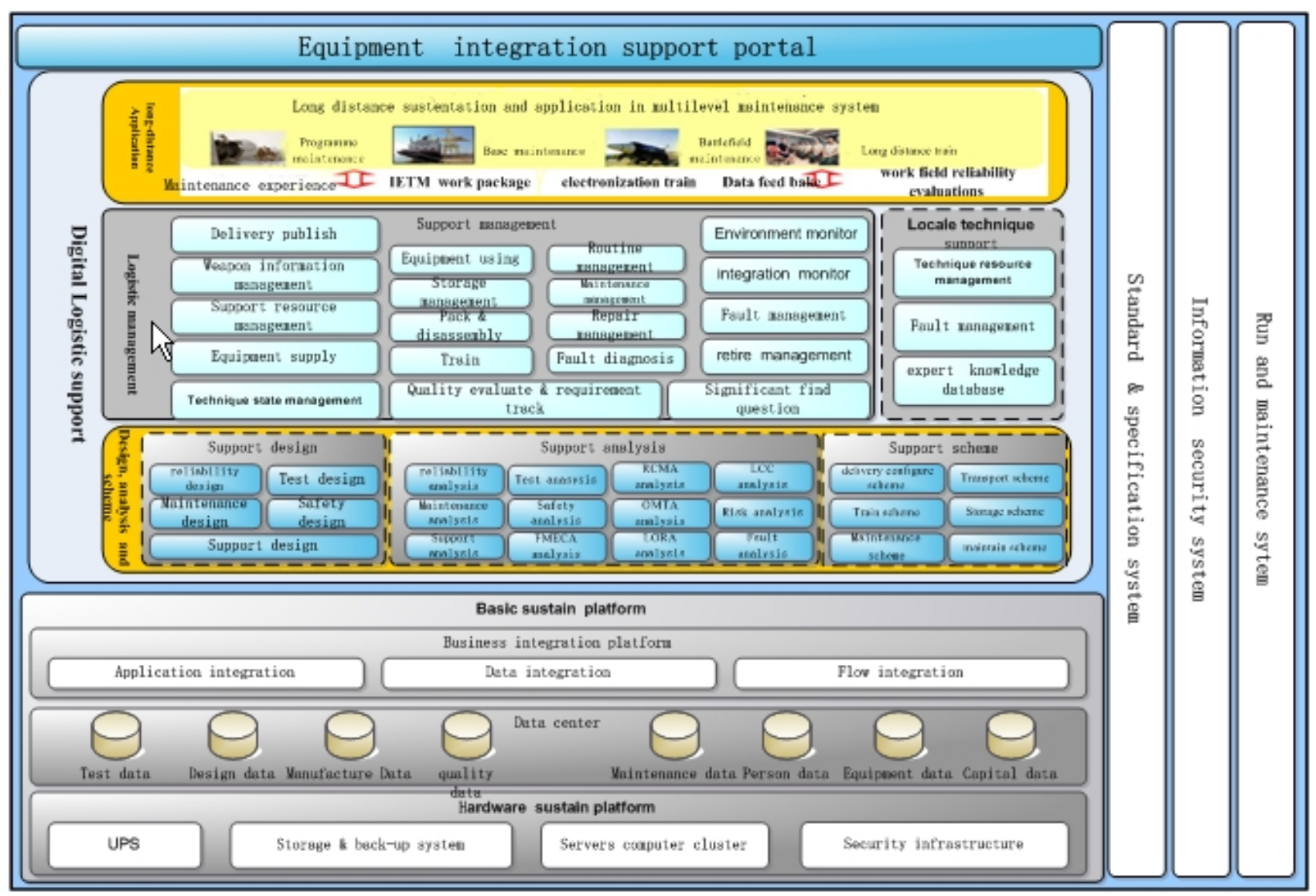

Figure 3. Information framework of equipment integrated support

\section{A. Support Design Analysis and Plan}

The design and analysis of the system is mainly used by the equipment design, mainly including the design system, the support system and the program system. Support design system will be integrated support requirements for the top five decomposition design. It carries out five decomposition index distributions. Collaborative design will be designed to equipments' all components, thus realizing the equipment reliability, maintainability, testability, support and safety design and analysis. Support analysis system is used for reliability analysis, maintainability analysis, test analysis, support analysis, support analysis, analysis, failure mode effect and criticality analysis, reliability centered maintenance and maintenance work, analysis of repair level analysis, life-cycle cost analysis and other aspects of support fault analysis. It provides the design results verification and stores design, analysis and verification of the result in the whole life cycle of the database, which is to achieve the exchange of data between the system design and comprehensive support. Support scheme of the system is formulated according to the factory equipment configuration, equipment maintenance plan, equipment maintenance plan, spare parts supply and equipment support training program scheme of system support analysis conclusion system design and support, and the support scheme of data feedback to the support analysis system, which is used to adjust and optimize the scheme according to the analysis conclusion. Then the equipment support scheme is on the basis of adjusted support optimized plan. Finally, equipment support management is implemented with support scheme.

B. Integrated Support Management and Technical Sustain

Integrated support management and technical support for comprehensive support management and field technical support in two parts, integrated support management equipment before delivery by the 
use of equipment development, integrated support management equipment delivered by use of equipment use, field technical support by use of equipment used.

Integrated support management includes the delivery of comprehensive distribution system, information system, support weapons equipment resources information system, use the navigation system, the daily management system, inventory management system, maintenance system, packing system, disassembly maintenance system, training system, monitoring system, fault system, fault diagnosis system, equipment supply system, technology demand management system quality assessment, tracking system, discovery research system. Delivery process, delivery information management to deliver products integrated support management, using IETM technology to complete the 0 to 5 level of IETM production, publishing; weapons and equipment to provide general information, proprietary information, along with data, affiliated equipments, tools, spare parts and resume information management; provide weapon equipment guarantee information resources management; provide equipment supply plan, supplies and classification, supplier management, accurately determine the scope and supplies by quota, shorten the average logistic delay (MLDT) and timely maintenance of equipment to improve the use of support availability; to provide covering maintenance and training, assembly and other usage scenarios using the navigation equipment to provide daily management; the information management of equipment before delivery and post delivery, including the relevant personnel and daily tasks; to provide the equipment before delivery After delivery and inventory management, including storage, warehouse, storage, warehousing and transfer; provide equipment before delivery and post delivery maintenance information management, including maintenance, standard operation procedures, plan, scheme, implementation process and personnel; provide equipment before delivery and post delivery packaging information management. Remove the standard, including packaging operation procedures, packaging, assembly, disassembly and other equipment; provide equipment maintenance plan and maintenance implementation process of information management; provide equipment training plan, training implementation process of information management; provide storage equipment storage, transport and use scenarios of environmental monitoring information, monitoring configuration and electronic monitoring information provide equipment management; changes of technical state management and equipment demand index tracking management, technical condition evaluation of equipment Change; provide the equipment using operation and maintenance process of problem records and problem tracking research and so on.

War field technical support including technical data management system, fault management system, expert knowledge base system, the required technical data to achieve the field management, complete closed-loop management field equipment fault occurs, provide fault diagnosis, maintainability analysis and maintenance level analysis, risk analysis, training and training required for expert knowledge management.

\section{Remote Applications}

Remote applications are mainly by the use of equipment. Remote applications include daily maintenance, base site maintenance, wartime repair, remote training and training, etc... In order to facilitate the equipment effectiveness analysis and evaluation, a new type of research, optimization, and improvement of life extend work, equipment users' data needs to feedback to the equipment developer. The data includes the site reliability assessment data, maintenance data, maintenance data base, repair data, training data, and wartime training data based on the IETM repair kit maintenance experience.

\section{Integrated Support portal system}

Integrated equipment support portal system is the integration of integrated equipment support related business systems. It will be equipped with comprehensive support related business system to access, generate affairs. The various departments such as equipment related design institutes, production units, the use of force, base warehouse, spare parts supplier collaboration etc work in coordination with of information and show through the portal system, which precipitates the application function, reflect the organizational level, data level and application level. Portal system uses SSO service system, the daily office no longer switched multiple systems to improve work efficiency. Data extraction, data display technologies are used to enrich the business system information display mode and to meet the decisionmaking layer comprehensive data on the timeliness, direct demand. It establishes business model, 
metadata, information encoding standard and unified standard for unified data collection, especially the acquisition of equipment condition monitoring data collection. The main functions of the integrated support portal system include the independent login of each business system, personalized content customization, multi channel access, portal content management and system performance maintenance, information release and display, etc...

\section{CONCLUSION}

Equipment support is in the same important position with equipment operational performance. Equipment support must be designed from the stage of equipment design, and continue to use the equipment throughout the entire life cycle of the entire process. Based on the analysis of the whole life cycle of the equipment support business connotation, this paper puts forward the integrated equipment support information goal oriented to the whole life cycle. The goal is to establish integrated equipment support platform, building the integrated data environment, digitization, automation and network to realize the whole life cycle of equipment information and integration, the integrated equipment support the information framework. It has a certain guiding role to promote the information construction of equipment support for the whole life cycle of equipment integrated support information system. Based on the framework of information construction, to promote the equipment life cycle cost effective reduction, promote the integration of equipment development and protection work, and promote the quality of equipment support, efficiency and capacity to improve.

\section{References}

[1] Xiao Huixin, Wang Jingbin, Peng Xiaolong.21, century foreign weapons and equipment information and Enlightenment of [J]. National defense science and technology, 2006 03: 17-20

[2] Fan Xiaojun. Research on information technology of equipment support in Modern Warfare [D]. master's degree thesis, National defense science and Technology University, 2006

[3] Xu Jin. Research on the information strategy of radar equipment support based on CALS [J]. modern radar, 2008, $30(10): 1-5$

[4] Lu Xincai, Liu Jingyang. Current situation and development trend of foreign [J]. equipment information construction project of national defense science and technology, 2007 02: 81-84

[5] Shang Li, Chen Li. The development trend of the information construction of the world's weaponry and equipment [J]. Journal of Military Economics Academy, 2005 03: 24-26 